\title{
Making the most of learning from home during times of crisis
}

\section{SABINA CLEARY AND CARMEN KENTON, with ROSEMARY HIPKINS and JOSIE ROBERTS}

Christchurch-based science advisers Sabina Cleary and Carmen Kenton, from Kaha Education, talk about their experiences of supporting teachers during the COVID-19 lockdown. Insights from their eperiences during a previous crisis guided them during COVID-19. They share their thoughts about useful learning to take forward as school life resumes.

Q. We were plunged into the COVID-19 lockdown so quickly, yet you two seemed to hit the ground running. What helped you to do that?

We learned a lot about home learning after the Christchurch earthquakes. Quite a few schools were closed and students were learning at home for some weeks. After the earthquakes we found that we had to streamline the curriculum and really pare it back. Kids don't have headspace to cognitively think things through in the same way they would at school. And they don't necessarily have the same level of support at home. The curriculum has to be streamlined for teachers' sakes as well. Many of them are being asked to do something they haven't done before, in a mode many haven't used before. So, both students and teachers need to be really clear about the plan and what they are trying to do.

After the earthquakes we saw that anxiety levels were high for many students and teachers, as with the COVID-19 lockdown. So we knew that any personal touch from teachers would make a huge difference for their students' wellbeing and learning. It could be a simple audio clip of your voice giving the instructions for a learning activity. If the students felt like it was you [the teacher] and that you had personalised the learning for them, we knew that would be helpful.

Q. So what advice do you have for teachers when they want or need to streamline units of work? Talk me though the principles you would apply, and the reasoning behind them. I am assuming here that these principles would also be useful for learning desgin more generally?

Our rule of thumb is to cut units back by around half. There is no way kids can get through what they would in the class. But even with content streamlining it is important for students to have opportunities to revisit the most important concepts several times. So prioritise what is important. Jonathan Osborne has talked about science learning as being like "marching frogs across the educational playground". We've got to stop the frog marching and cut down the number of 
things we think it is important for kids to know, and then we need to model the learning for them.

Units of work often need to be reordered. A sequence that seems to unfold logically in the classroom might not be so easy to follow when students are learning from home. We use David Perkins' metaphor of "whole" learning as a guide. Our aim is to have a unit begin with whole experiences that are already accessible to students, to act as a hook to get them interested.

Review the learning contexts in the unit. We say familiar experiences are the Velcro in the learning because they provide the hooks. Familiarity gives students a way to get started but as the unit unfolds it can be useful to keep some broader or more abstract contexts, providing they still have relevance to students' lives more generally. During the lockdown we heard from teachers who had thought about how to create learning activities around events taking place during life at home. They then designed activities to engage students in thinking about the concepts that they could see in those everyday activities. Examples included bread-making, baking, regular hand washing, pets, family trees and so on.

Prune your supporting resources. For example we often find that resources such as videos are only partly relevant and can contain additional material that could be confusing for students who are watching and learning at home on their own. Make sure all the resources you do keep are going to be practical for students working at home, or in self-directed learning at school.

What about assessment? Our conversation came about because of an assessment resource you shared with me. I think many readers will be interested in that challenge too.

During the lockdown teachers worried about the sorts of evidence of learning they could legitimately count. We encouraged them to get into the habit of briefly documenting anecdotes that catch significant learning moments for students. We produced a pamphlet with a focus on "naturally occurring evidence" to share our advice about gathering this type of data.1

Our general message is not to wait until the end of the

"... even with content streamlining it is important for students to have opportunities to revisit the most important concepts several times. So prioritise what is important." unit of work to do a test. Where we can, we adapt and use Assessment Resource Bank (ARB) items within a unit of work. These have the advantage of modelling formative use of students' responses from a larger population of students. This information provides a context in which teachers can make sense of their own students' responses to the same or a similar task.

When students are not physically present at school it can be helpful to provide support for metacognition. We have created reflection sheets to go with units of work. We have also provided tips for setting up "virtual bubble groups" (typically of three students) for reflecting on learning and learning support more generally. Although some teachers have told us that not all students liked working in virtual small groups. We don't know why. We still need to get to the bottom of this feedback.

It must have been so hard for teachers who had not engaged with digital learning opportunities before the lockdown. What tips can you share that might be helpful for thinking about professional learning going forward from now?

Begin with digital communication basics. We became aware that some students and teachers haven't had experience of opening and saving, uploading and downloading, and remembering passwords. Also, if your only communication means is by email, that makes a lot of work for teachers-downloading and saving students' attachments and so on. For students who are our digital natives email can be very old-school. We saw a student struggle to attach a document to an email, even though he usually learns in a 1:1 context where each student has their own device. If what you are used to doing is posting to Google Classroom, and using Teams and Seesaw, these "old" basics might not be as obvious as we assume. And even Google Classroom can seem old-school to students who do most of thier interacting in social media contexts. So, as well as digital basics, teachers also might want to explore different platforms with their students.

Carmen, you were still teaching at the time of the Christchurch earthquakes. What can you share for teachers who found themselves less prepared for home learning when schools closed this time?

The last crisis is actually what launched me into e-learning. We were out of school for 6 weeks and I realised that I really enjoyed finding digital solutions for my students. I pushed on, using e-learning more and more in class, so that children would have confidence when they were 
out of class. For example, I came to love Learning Tools, which gave more control to students. I also pushed hard for a digital learning system in the school: at the time it was Moodle.

Now students are back in in school, do you have suggestions for how to ensure learning resiliency given the uncertainty about how COVID-19 might play out overtime?

We found that schools that had a digital learning system in place prior to COVID-19 were able to adapt more quickly to lockdown. We recommend that schools introduceor ramp up - a school-wide digital system now that everybody is back on site. Teachers could also explore different platforms or apps with their students, taking students' lead on what might support the social nature of learning to continue if we find ourselves in lockdown again. Most of all, enjoy the relationships. Strengthen them for the future, both within the school and between home and school.

\section{Note}

I. https://www.kahaeducation.co.nz/articles/naturallyoccurring-evidence
Sabina Cleary is an accredited secondary facilitator for Kaha Education. She was a medical technologist and then a science teacher prior to 9 plus years as a curriculum and learning facilitator at UC Education Plus, and now Kaha Education.

Email: sabina@kahaeducation.co.nz

Carmen Kenton is also an accredited secondary facilitator. She has been an educator for over 20 years and joined Kaha Education in 2018 after 13 years as head of a science department in a large secondary school in Christchurch.

Email: carmen@kahaeducation.co.nz 